\title{
FISH SPECIES ECOLOGY IN SPANISH FRESHWATER ECOSYSTEMS
}

\author{
C. Granado-Lorencio \\ Departamento de Biología Vegetal y Ecología. Facultad de Biología, Apdo. 1095, 41080 Sevilla. Spain.
}

Keywords: Fish assemblage, Life-history, Fluctuating stream, Spain.

\begin{abstract}
The life strategies of the Iberian ichthyofauna, poor in species and with a high number of endemisms, are the result of the functioning of the aquatic systems (streams and reservoirs). The majorety of the species wager for iteroparity, high fertility, predominance of males over females and omnivorous feeding habits (short- chain trophic relationships). The fish assemblage is not very structured and depends on the autoecology of the species.
\end{abstract}

\section{A HISTORICAL APPROACH}

Two factors determine, or have determined, life strategies and structure of the fish assemblages in Spanish freshwater ecosystems: biogeography of the species and functioning of the aquatic systems. Relatively recently (from the beginning of the twentieth century), reservoir construction policy has resulted in adaptive divergences from the general patterns.

The Iberian Peninsula is in the extreme south of the continent, as a bridge towards Africa. The Pyrenean mountain system and the Straits of Gibraltar give this enclave singular biogeographical characteristics. In contrast to the diversity of the Palaearctic region and the European continent, the Iberian fish fauna comprises just two freshwater families (Cyprinidae and Cohitidae), and ten with a certain tolerance to saltwater, of marine origin or with a cycle shared between river and sea (Cyprinodontidae, Acipenseridae, Anguillidae, Clupeidae, Salmonidae, Sygnatidae, Gasterosteidae, Blenidae, Gobiidae and Cottidae). Of the 61 Iberian species (44 native and 17 exotic), the Cyprinidae are the majority (22 species). The isolation of the area has determined the postoligocenic differentiation of the present-day Iberian endemisms (16 taxa). The exotic species belong to the families Esocidae, Ictaluridae, Poecilidae and Centrarchidae.

At the same time, the region is poor in lentic ecosystems, and the river systems are not very large compared with others in the world. Most of the Iberian river systems are characterised by their intermittence, with periods during the

Limnetica, 8: 255-261 (1992)

O Asociación Española de Limnología, Madrid. Spain year of torrential rain and drought, typical of semiarid and arid geographical areas. Moreover. the seasonal irregularity of the rainfall causes marked differences in the interannual flow. These hydrological peculiarities have determined the water policy of the present century, with the construction of more than 1200 large dams (481 between 1938 and 1973). Something over $45,000 \mathrm{Hm}^{3} /$ year of the flow is controlled ( $40 \%$ of the total flow). To sum up, it can be said that the Spanish aquatic environment comprises few lakes and lagoons, with a group of sh ort hydrographic networks of irregular, seasonal flow, controlled along practically their whole length by reservoirs.

In this "hydrological schizophrenia", the Iberian ichthyofauna - poor in species, with a high number of endemisms (as a result of isolation), and evolving in the functional framework of natural environments (rivers), some of which resemble those of the past while others are totally disconnected from current reality (by reservoirs and the reaches below them) - uses its life strategies to survive. Paleoautoecology and "adaptive reconversion" is the evolutionary wager for the Iberian ichthyofauna.

\section{RIVER ICHTHYOFAUNA}

The Iberian river ichthyofauna comprises three species types: sedentary and potamodromous natives, sedentary exotics, and migratory species (anadromous and catadromous). 
The recent history of the Spanish migratory species is a phenomenon with scarce data. Their abundant populations in historical times were due to the location of the Iberian Peninsula in the migratory path of temperate diadromous fish species to the north Atlantic Ocean and the Mediterranean. The most important migratory fish species of the Iberian Peninsula were sea lamprey (Petr-omyzon mar-inus ), Atlantic salmon (Salmo salar-), sturgeon (Acipenser sturio), European eel (Anguilla anguilla), shads (Alosa $s p p$ ) and mullet (Chelon $s p p$, Liza $s p p$, Mugil $s p p$ ). Since the early twentieth century, the blocking of upstream migration by reservoir construction has led to a progressive decline in the populations of the Iberian migratory species. Some of them are very scarce or have disappeared (sea lamprey, sturgeon. Atlantic salmon and shads); European eel and mullets are still abundant in the lower reaches.

As stated above, the family Cypr-inidae is the most interesting group of the Spanish ichthyofauna (for its number of species and endemisms, fish assemblages, feeding habits, etc.). The Iberian Cyprinidae are characterised by short age pyramids (few age classes); short lifespan; early sexual maturity (between the second and fourth year of life); high levels of fertility, in one or more reproductive periods during the year ( 3000 to 8000 ovocytes per mature female) varying according to age; the sex ratio usually favours the ma les (with interannual variations); the reproductive season is associated to the spring and early summer; high levels of mortality both at population recruitment level and throughout the age classes; cyclic growth rhythm, synchronised with the most favourable period and of 3 to 5 months in duration (slowing down or becoming zero in summer and winter).

There are rheophile species (mainly Iberian barbel and nase) which migrate upstream to reproduce, in search of zones with current, gravel and sand bottom, and well oxygenated (RODRIGUEZ, 1992). The beginning of migration appears to be related to water temperature (between 12 and $14^{0} \mathrm{C}$ ). It does not usually last more than one month (determined by the migratory distance). Occasionally it takes place globally (continuous flow to the reproduction aseas), and in some species (barbel) in a series of spurts. In both cases, retur $\mathrm{n}$ to the normal areas of occupation is en masse. These reproductive movements, in the Iberian rivers, should not be considered as di splacement of the whole population to a single zone of the river (as with the salmon), but more a displacement of population groups localised in different sectors of the river that move upstream and reproduce in different zones ("meet and spawn hypothesis").
Feeding is at four trophic levels: detritus, phytobenthos, benthonic macroinvertebrates, and emergent forms. Exploitation is sometimes at a single level (Chondr-ostoma-detritus) and sometimes at several levels (Barbus-macroinvertebrates, phytobenthos, drift). There can even be an ontogenic variation of food within the same species (Leuciscus-fry (algae and zooplankton), adults (microcarni vorous)). Ichthyophagy is rare in Iberian fish, although fish remains can be found sporadically in analysed stomachs.

Thus the taxa in the Iberian river communities show a low trophic diversity, due to their similar adaptations to an environment whose fluctuation prevents more sophisticated evolutionary wagers. This incurs the need to develop timeseparated patterns of resource exploitation (segregation), when the feeding resource, if unequal, is spatially in the same microhabitat. Generally (DIANA, 1979), it may be said that with more ichthyophagy, the daily feeding rhythm is more acyclic. Herbivorous, benthophagic, and other behaviours produce cyclic rhythms, which can be diurnal or nocturnal, depending on the type of prey, competitive phenomena, etc. The latter feed continually or during a long period of the day and digest while they eat (they obtain little energy from the food, forcing them to eat a lot - high energy cost in feeding). The others eat rapidly (over a short period) or several times a day, and digest the food before eating again (they obtain high energy from the food and do not need to eat frequently - they spend little energy in feeding). The detritovores obtain little energy from the food, forcing them to eat continually, while the herbivores obtain somewhat greater energy yield from the food, so that they do not need to be continually feeding. The results obtained by ENCINA \& GRANADO LORENCIO (1991) in a study of diet and diel feeding chronology in three endemic species demonstrate this phenomenon. Iberian nase (detritovores) have a mean energy from a full stomach of $1450 \mathrm{cal} / \mathrm{g}$ dry, ash-free weight, Iberian barbel $3600 \mathrm{cal} / \mathrm{g}$, and chub $5000 \mathrm{cal} / \mathrm{g}$.

The conflict comes when the feeding habitat coincides, even though the food does not. On these occasions, the species temporarily displace their daily feeding cycle so as not to interfere with each other. The latter authors found that the nase has maximum feeding between solar hours 19 and 20 , while for the barbel it is between 13 and 15 , in a sector of the river in which the benthonic habitat is not very diverse and the zones of sediment accumulation are scarce. When there is great diversity of trophic habitats for the species, there is no need for displacemeiit - the barbel maintains the same timetable and the nase takes the hours 14 to 
16, much closer to the other species (which may be its potential feeding rhythm in non-competitive conditions).

Fish inhabit a patchy environment (TOWNSEND, 1989), reconnoitring the habitat to exploit the available resources necessary for their growth, base metabolism, and reproduction. They move in function of the spatial concentration of the trophic resources. If the resource is abundant and uniformly distributed, there is no need for a large home range. In contrast, if the resource is scarce or very concentrated, they need to range over a very large area to obtain the energy necessary (WIENS. 1976). Moreover, as the Iberian river s fluctuate throughout the year, sometimes we find large home ranges and other times small ones (necessarily so at low water). Better quality habitats produce more restricted living domains (MATTHEWS, 1990). How do the Iberian Cyprinidae behave?. The response is a little speculative: there are not enough data. If we consider the results obtained by PRENDA \& GRANADO LORENCIO (in press), using phytobenthonic production as potential indicator of the available resources and hydrology of the different reaches of the stream, we find some interesting behaviour. In the high reach of the stream during winter, when there is still a great amount of food in the riffles and raceways, these are the least occupied (mechanical incapacity). The pools, although with less food, are more visited (there is a negative gradient of current speed nearer the bottom of the pool). That is, the pool is a shelter against the periodic winter disturbance. However, when the river is wider and less deep, with a greater capacity to reduce the disturbing effect of spate (mi dreach), the ichthyofauna is spatially structured in a different way. Below a certain speed, the fish is able to keep swimming and overcome the drag effect, occupying the zones of the river with greater resources. If we could see what happens in other parts of th e year, with less flow, the tendency would probably be towards the riffles.

If a greater home range is needed with greater concentration of resources, the response of the Iberian Cyprinidae in the results obtained by the latter authors does not disagree with the conclusion of WIENS (op. cit.): species have a smaller home range when the re sources are uniformly distributed.

Estimates of biomass and production can be used to quantify "degree of welfare" of the populations. The existing data for Iberian rivers are few and to some degree incomplete (no data for temperature regime, nor primary and secondary production, or any other measu rement permitting integration of fish production value into the aquatic ecosys- tem). The estimates per species vary between 54 and 590 $\mathrm{Kg} / \mathrm{Ha}$ in biomass and between 21 and $353 \mathrm{Kg} / \mathrm{Ha} /$ year in production (values of $\mathrm{P} / \mathrm{B}$ between 0.49 and 0.70 ) - higher values than those obtained in most European rivers. There are distinct causes: predominance of Cyprinidae in the assemblages; scarce, low diversity; and high thermal regime in the rivers. Nevertheless, partial analysis of these results may lead to erroneous interpretations. Values of this type may result from the confluence of positive environmental factors in a particular year, due to the unpredictability of the mediterranean environments and the autoecology of the species. However, lengthy following of biomass and production would undoubt edly show the strong interannual fluctuations which are typical of this type of ecosystem subjected to physical disturbances (STRONG , 1983).

\section{RESERVOIR ICHTHYOFAUNA}

Three life-cycle-types of species can be found in Spanish reservoirs. There are those that live their whole cycle in the reservoir (common carp, goldfish, tench, pumpkinseed, black bullhead, largemouth bass, mosquitofish, and pike); those that migrate to the high reaches of the rivers to reproduce (barbel and nase); and those that have remained trapped in the reservoir in their trophic or reproductive migration from the sea (mainly sandsmelt and eel). In coldwater reservoirs, it is possible to find certain native or introduced salmonids (Salmo trutta, Onchorrynchus mykiss and Salvelinus fontinalis).

There have been few studies at ichthyofauna level in Spanish reservoirs. Nevertheless. the results obtained throw light on the effec $t$ of the reservoir on the fish populations. It has been possible to demonstrate the interaction between limnology and plasticity of the species in a comparative study of populations of Iberian nase (Chondrostoma polylepis) from three in-chain reservoirs of the Tagus River : Valdecañas, Torrejon and Arrocampo. The factors having greatest effect on growth are primary productivity of the water mass (expressed as units of chlo rophyll "a") and mean depth of the reservoir (GRANADO LORENCIO et al., 1985).

The spatial, temporal, and bathymetric distribution of the populations in the reservoir depend on endogenic-type factors (reproductive cycle) - genetically fixed - and exogenic ones (environmental) - determined by the physico-chemical variables. The river origin o f certain species (mainly barbel and nase), which move upstream for 
reproduction, determines the maintenance of this type of cycle once they occupy the water mass of the reservoir. For a relatively long period of the year (generally from February to May or June, depending on the species), the populations go up the tributaries in search of zones of well oxygenated, clear water with sand or gravel bottom, where they spawn. In this way, the species assure their maximum reproductive viability, and temporarily exploit the production of the river, functioning as "a mature ecosystem which exploits other less mature ones" (c.f. MARGALEF, 1960). This process results in swings of population to the rivers at spawning, on one hand, and recruitment of young individual to the reservoir population, on the other. Other species, belonging to the genus Cyprinus, Carassius. Micropterus, Esos, Lepomis, etc., reproduce in shallow zones of the reservoir with vegetation, migrating within the reservoir from the areas of normal localisation to those of reproduction.

The exogenic factor is determined by the annual evolution of certain limnological parameters of the water mass. The reservoirs in these latitudes have annual holomicticmonomictic cycles. Stratifications are established during the summer period and a potent hypolimnion develops which increases with depth and eutrophycation level of the reservoir. The cyclic behaviour of the phenomenon precludes a homogenous distribution of the ichthyofauna, which is localised in surface layers and shallow creeks.

The period of stratification does not affect only the general pattern of population distribution, varying the home range of the species. It also has a very important effect on the feeding regime of those species having a benthonic and/or detritophagic diet (the majority of the natives), since during this period the potentially exploitable resource is reduced to those areas where the hypolimnion does not develop.

If the food of the species in the river is based on detritus, periphyton, and drifting and benthonic macroinvertebrates, associated with the large number of habitats in the river courses, colonisation of the reservoir alters this feeding regime. The trophic chain of the reservoirs is not very diverse (unless there are exotic species) due to the drastic reduction of habitats and scarce structuring of a truly benthic littoral, as a result of the continuous variations in level. Because of this, and the anatomic-structural incapacity of the species to exploit the new resources (mainly phytoplankton and zooplankton), the reservoir leaves few possibilities of a wide diet for the species (GRANADO LORENCIO \& GARCIA NOVO, 1986).
The production of phytoplankton and zooplankton is not efficiently exploited by the fish, and sediments on the bottom (a process tha $t$ may increase in cases of high eutrophy). A great part of the available energy in the system is channelled detritically and benthon ically. The only trophic strategy of the native species is the exploitation of both subsystems. This implies diets based on detritus, insect larvae (mainly chironomids, being one of the few groups represented), and bankside phytobenthos. However, it is not unusual to find planktonic elements in the alimentary tracts. The latter can be interpreted as "passive" feeding, forming part of the diet without localisation and capture on the part of the fish. It enters the stomach only as a result of the abundance of prey in the medium, being ingested with this other, actively hunted prey.

If the absence of species able to exploit the plankton and ichthyophage levels (excepting the introduced species) is added to the sc arce structuring of Spanish reservoir assemblages, the development of evaluative fishery models such as those applied since the 50s in other countries is difficult (SCHNEIDER \& HAEDRICH, 1989). In view of this, a study was carried out in seven reservoirs in the south of the Iberian Peninsula (GRANADO LORENCIO \& SANCHO, 1987). The aim was to study the behaviour of different climatic. edaphic, soil-use, limnological, and fish production variables, to detect which were most important, using multiple regressions. The two variables best related with reservoir biomass were average depth and the shoreline development factor.

There are works which demonstrate the relationship between environmental variability and community structure. The assemblages do not depend only on the phenomena of competitive interaction. If the populations have no problems in exploiting the resources, their swi ngs are caused by other factors (EBELING et al., 1985). This is the case of the Torrejon reservoir (GRANADO LORENCIO, 1991). There was a large variation in population number throughout the period 1980-1988. Spanish reservoirs have characteristics which make the system relatively unstable: swings of level, hypolimnetic water outflow, etc. The effect on the ichthyofauna depends on the autoecology of the species. Population stability is the result of interactions between the effect of environmental changes (disturbances) and the adaptive capacity of the species. The disturbing factors can vary fish association in different ways, depending on the impact and effect on each taxa. The species of the lberian reservoirs are of an elastic and high reproductive rate type, and thus eventually tend to return to the pre-disturbance state. 


\section{THE SPANISH FISH MODEL}

The life strategies of the extant species can be understood only within the framework of biogeography and the functioning of the ecosystems which they inhabit. From a pool of species which colonised the Iberian rivers in the past, and from the evolution of their hydrological regime, it is possible to understand the biological patterns developed by these species. Up to a point, some of them have developed recently, and change (although minimally) in each annual cycle (occupation of space, variations in the qualitative composition of diet, changes in the population through catastrophic losses in recruitment). Others are possibly the inheritance of a past much more adverse than the present, as in the upstream migratory behaviour for reproduction (typical of colder eras).

The ichthyofauna of most lberian rivers has life strategies that show the best possible adaption to an irregularly fluc- tuating envir onment. It is possible to observe different forms of organisation of the fish communities or assemblages (fig. 1 ). When the time variation is small, the species can develop strategies to exploit resources and occupation of space which occasionally lead to competitive relationships. In those rivers, the "community" may be controlled by the niche or by phenomena of dominance by one species (YODZIS, 1986). These communities typically comprise native or introduced salmonids and other species with scarce populations.

In contrast, in stream with greater time variation (typical of the Iberian Peninsula), assemblage is not very structured and depends on the autoecology of the species. To lessen the effect of disturbances, the majority of the species wager for iteroparity, high fertility, predominance of one sex over the other, and possibly even monosex populations (although there are no reliable data on those processes). These are explosive population phenomena which counteract losses due to environmental factors, omnivorous feeding habits, and

\section{SPECIES}

\section{$K_{\text {SELECTION }}$}

\section{'SELECTION}

\section{ASSEMBLAGE DOMINANCE / NICHE}

COMPETITIVE LOTTERY

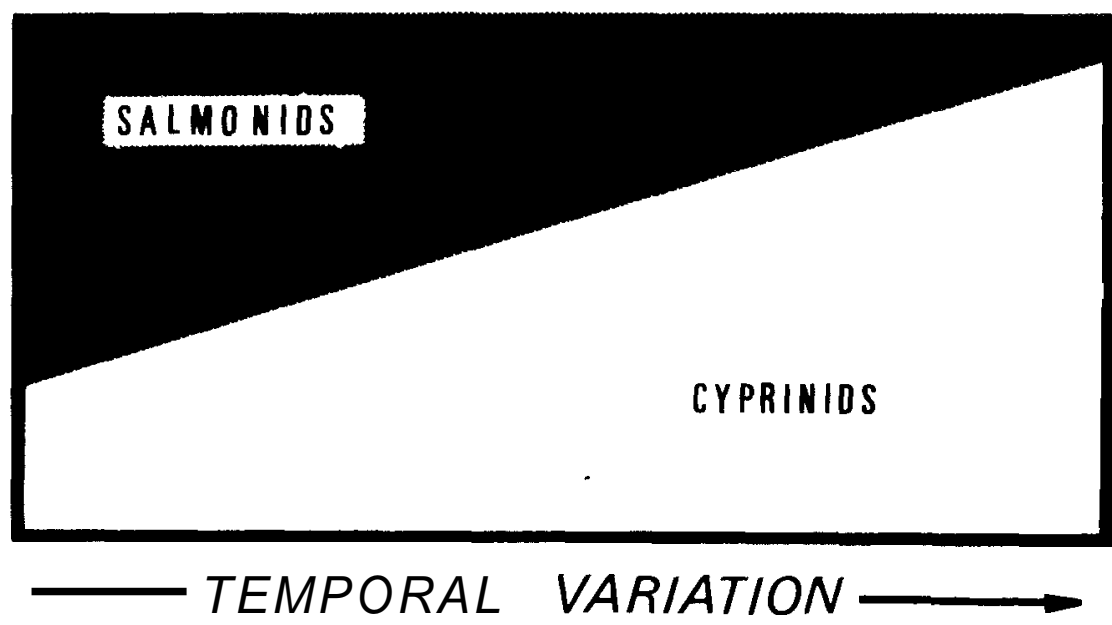

\section{ENVIRONMENT LOW}

HIGH

UNPREDICTED

STREAM reservoir

Figure 1. Schematic relationships between temporal variation and life strategies and control of fish assemblages in spanish aquatic ecosystems. 
short-chain trophic relationships, etc. Higher specialisation might be a $c u l-d e-s a c$ in a strongly fluctuating environment.

Assemblages respond more to an individual strategy of survival than to the result of competitive interactions. Environmental fluctuations impede stable structuring of the "community", producing continual processes of reorganisation following the destructive phenomena caused by floods and very low waters. Thus it is understandable to find associations in neighbouring rivers, formed by three species or more than eight, depending exclusively on the biogeographical component. This type of association in the Iberian rivers is a good example of the "competitive lottery model" (WARNER \& CHESSON, 1985).

From a synecological point of view, the relationships between functioning of the river and autoecology of the species are obvious. In the rivers of the mediterranean region, there is a general destruction of biological associations during the winter period. The high torrential flow removes everything that existed previously. As the environmental conditions become more favourable in the spring, aquatic organisms begin to recolonise. The invasion involves an acceleration in the life cycles, and thus high biological production that is transferred to the higher levels of the trophic chains of the river.

In this annual pattern, what is the best adaptive role for the ichthyofauna?. The synchronisation of its life cycle to exploit resources as efficiently as possible and optimise the viability of its descendants. The species reduce the feeding level during winter, with zero growth (unfavourable period). In spring, trophic resources are used with more diverse feeding strategies; the beginning of the somatic growth period; and part of the energy consumed is transferred to the production of reproductive tissue. Most species reproduce in this period or at the beginning of summer. Synchronisation is perfect when it is seen that eclosion of the larval forms takes place in summer, the period when there is greatest abundance of small-sized prey (diatoms, bankside plankton, and others) - the food base of the individuals of class $\mathrm{O}+$ in most species.

The reservoirs are at the other extreme of time variation. Here, the importance of this factor is not so much its size as its unpredictability. The seasonal disturbance of the stream is internalised by the species (synchronisation), but that due to reservoir management is not. Consequently, only those species having a high degree of opportunist life cycle or selection, with reproductive migrations out of the reservoir or with omnivorous feeding habits, will be capable of remaining in the reservoir.
Undoubtedly, the environmental severity of stream in the mediterranean region is a good "learning ground" for the Iberian species which colonise reservoirs. Those able to make the evolutionary wager of all-or-nothing are the best prepared to survive in man-made environments which currently make up the greater part of the aquatic environments of this region.

\section{REFERENCES}

DIANA, J.S. 1979. The feeding pattern \& daily ration of a top carnivore, the northern pike (Esoxlucius).Can. J.Zool. 57: 2121-2 127.

EBELING, A.W.; LAUR, D.R. \& ROWLEY, R.J. 1985. Severe storm disturbances \& reversal of community structure in a southern california Kelp forest. Marine Biology 84: 287-294.

ENCINA, L. \& GRANADO LORENCIO, C. 1991. Diet $\&$ diel feeding chronology of three iberian fish species. Ecology International Bulletin 19: 43-64.

GRANADO LORENCIO, C.; GUILLÉN, E. \& CUADRADO, M. 1985. The influence of some environmental factors on growth of iberian nase, Chondrostoma polylepis, in three reservoirs of western Spain. Cybium 9 (3): 225-232.

GRANADO LORENCIO, C. \& GARCIA NOVO, F. 1986. Feeding habits of the fish community in a eutrophic reservoir in Spain. Ekologiu Polska 34 ( 1):95-1 10.

GRANADO LORENCIO, C. \& SANCHO, F. 1987. Producción piscícola en siete embalses españoles: Memoria de un Proyecto y resultados preliminares. Actas IV Congreso Español de Limnología: 359-367.

GRANADO LORENCIO, C. 1991. Fish communities of spanish reservoir systems : a non-deterministic approach. Verh. Internat. Verein. Limmol 24:2428-2431.

MATTHEWS, K.R. 1990. An experimental study of the habitat preferences \& movement patterns of copper, qullback \& brown rockfishes (Sebastes spp.). Env. Biol. Fish. 29: 161-178.

MARGALEF, R. 1960. Ideas for synthetic approach to the ecology of running waters. Int. Rev. Gesamten. Hydrobiol. 45: 133-153.

RODRIGUEZ RUIZ, A. 1992. Comunidad ictica y estructura del háhitat en un rio de régimen mediterráneo. Doctoral Dissertation, Sevilla University, Spain, p.p. 430.

SCHNEIDER, D.C. \& HAEDRICH, R.L. 1989. Prediction limits of allometric equations: a reanalysis of Ryder's 
morphoedaphic index. Can. J . Fish. Aquat. Sci. 46: 503508.

STRONG, D.R. 1983. Natural variability \& the manifold mechanisms of ecological communities. Amer. Natur. 122: 636-660.

TOWNSEND, C.R. 1989. The patch dynamics concept of stream community ecology. J.N. Am. Benthol. Soc. 8 (1): $36-50$.
WARNER, R.R. \& CHESSON, P.L. 1985. Coexistence mediated by recruitment fluctuations: a field guide to the storage effect. Amer. Natur. 125: 769-787.

WIENS, J.A. 1976. Population responses to patchy environments. Ann. Rev. Ecol. Syst. 7: 81-120.

YODZIS, P. 1986. Competition, mortality \& community structure, p.p. 480-491. In J.M. Diamond \& T.J. Case (eds.). Community ecology. Harper \& Row, New York. 